\title{
Can Registration Procedures of Pharmaceuticals Inadvertently Contribute to Off-Label Prescribing in Children?
}

Therapeutic Innovation \& Regulatory Science

1-9

(C) The Author(s) 2016

Reprints and permission:

sagepub.com/journalsPermissions.nav DOI: $10.1|77 / 216847901665| 470$

tirs.sagepub.com

\author{
Ian Ellul, BPharm(Hons), PhD', Victor Grech, MD, PhD, FRCP(C)H, MRCP, DCH, CLJ', \\ and Simon Attard-Montalto, MBChB, MD, FRCP, FRCP(C)H, DCH
}

\begin{abstract}
Background: In Malta, off-label prescribing of medicines in children stands at $45 \%$, mainly because of failure by prescribers to follow the dosing recommendations in the product literature. In addition, registration procedures of pharmaceuticals may inadvertently contribute to this high incidence of off-label prescribing. Methods: A literature review was conducted to identify regulatory provisions relating to the registration of medicines in Malta that could give rise to off-label use. Furthermore, the product literature of the 2 classes of medicines most commonly prescribed in children, antibiotics and respiratory medicines, were reviewed. This was done in order to gauge whether the different registration routes implemented in Malta to market these medicines could give rise to off-label use. Results: The national registration procedure relating to Article I26a of Directive 200I/83/EC and, to a lesser extent, line extensions, parallel importation, and the provision detailed in Article II of Directive 200I/83/EC were found to lead to discrepancies and potentially misleading inclusions in the product literature. These, in turn, may well contribute to off-label use of medicines in children. Conclusions: Off-label prescribing does not necessarily mean that efficacy and safety data are unavailable. Variances in the product literature of medicines having the same active ingredients but imported from different countries may cause divergent prescribing practices, leading to inadvertent off-label use. The various stakeholders, including member states such as Malta, should devise strategies to harmonize the most recent labeling information in order to support the safe and effective use of pediatric medicines, thereby decreasing off-label use.
\end{abstract}

\section{Keywords}

off-label, children, referral procedures, Directive 200I/83/EC, Article 126a

\section{Introduction}

Article 179 of the Treaty on the functioning of the European Union (EU) states that "the Union shall have the objective of strengthening its scientific and technological bases by achieving a European research area in which researchers, scientific knowledge and technology circulate freely, and encouraging it to become more competitive, including in its industry, while promoting all the research activities deemed necessary by virtue of other Chapters of the Treaties." ${ }^{1}$ In this respect, European legislation aims to ensure that safe, good-quality and efficacious medicinal products are freely marketed within the EU.

Medicines for human use are marketed in a member state after a marketing authorization has been granted. This regulatory requirement traces its origins to Council Directive 65/65/ EEC of January 26, 1965, which laid down the 3 basic criteria on which marketing authorizations are based: quality, safety and efficacy. ${ }^{2,3}$ In Malta, the smallest member state of the EU, pharmaceutical regulation is governed by the Licensing
Authority, which is the Maltese competent authority, enacted through the Medicines Act (Act III of 2003). ${ }^{4}$

European legislation details 2 types of authorization routes, European and national, used to approve medicines in member states. European procedures include the centralized authorization procedure, mutual recognition procedure, and decentralized procedure. These procedures involve the simultaneous placing of medicines in different member states. In order to obtain a community authorization across all Europe through the centralized authorization procedure, the marketing authorization holder needs to submit a marketing authorization

\footnotetext{
'Department of Paediatrics, Faculty of Medicine and Surgery, University of Malta, Msida, Malta

Submitted 25-Jan-2016; accepted 2-May-2016

Corresponding Author:

lan Ellul, BPharm(Hons), PhD, Department of Paediatrics, Faculty of Medicine and Surgery, University of Malta, Msida, MSD2080, Malta.

Email: ian.c.ellul@gmail.com
} 
application to the European Medicines Authority (EMA). Medicinal products authorized through the centralized authorization procedure can be automatically marketed in all member states, including Malta. The marketing authorization holder may also opt for a decentralized procedure to obtain a marketing authorization in specific member states. However, when a medicinal product is already authorized in a member state and the marketing authorization holder needs to market it in other member states, the mutual recognition procedure applies. In the case of decentralized and mutual recognition procedures, an application needs to be submitted by the marketing authorization holder to the competent authority of those member states in which the marketing authorization holder intends to market the product.

Apart from these European procedures, which involve a number of member states, there are also national authorization mechanisms used by individual member states to register medicinal products in their territory. The principal national registration procedures used by the Maltese Licensing authority are line extensions, parallel importation, and the provision governed by article 126a of Directive 2001/83/EC. ${ }^{5}$ Line extensions are marketing authorizations granted to medicines as detailed in Annex I of Commission Regulation (EC) No. 1234/2008. ${ }^{6}$ These include instances where there are changes to the active ingredient, strength, pharmaceutical form, and route of administration of medicinal products which are already authorized in a particular member state. On the other hand, parallel importation is governed by the Commission Communication on parallel imports of proprietary medicinal products for which marketing authorizations have already been granted $\left(\operatorname{COM}(2003) 839\right.$ final). ${ }^{7}$ Parallel importation is the importation of a specific medicinal product, already authorized in a particular member state, from another member state, by a wholesale dealer other than the officially appointed wholesale dealer authorized by the marketing authorization holder. In Malta, parallel importation is regulated by the Parallel Importation of Medicinal Products Regulations (458.40). ${ }^{8}$ The rationale for parallel importation arises from cross-country price variability between source and destination countries for the same medicinal product. A third national registration procedure is based on article 126a of Directive 2001/83/EC, also referred as the "Cyprus clause." Article 126a states that "in the absence of a marketing authorisation or of a pending application for a medicinal product authorized in another Member State in accordance with this Directive, a Member State may for justified public health reasons authorise the placing on the market of the said medicinal product." 2 Article 126a of Directive 2001/83/EC has been transposed in Malta as Article 3(2a) of the Medicines (Marketing Authorisation) Regulations (SL 458.34). ${ }^{9}$

In order to gain either a European or national marketing authorization, the marketing authorization holder needs to submit specific documentation to the competent authority as part of the marketing authorization application. This includes the summary of product characteristics and the patient leaflet. The summary of product characteristics, whose content and structure are defined in Directive 2001/83/EC, is an important legal document since it provides guidance on the appropriate use of a particular medicinal product. In particular, section 4.1 of the summary of product characteristics specifies the therapeutic indications including the age groups in which the medicinal product is indicated and section 4.2 relates to the posology, specifying the dose recommendations for each age band detailed in section 4.1. ${ }^{10}$

When prescribers recommend the use of a medicine in ways other than those detailed in the summary of product characteristics, this constitutes off-label use. The only European legislation text that defines off-label use is Directive 2001/82/EC, relating to veterinary medicines. ${ }^{11}$ It defines off-label use as "the use of a veterinary medicinal product that is not in accordance with the summary of the product characteristics, including the misuse and serious abuse of the product." ${ }^{12}$ The only other non-legislative document which defines off-label use of medicines in humans is Annex I to the Guideline on good pharmacovigilance practices, published in 2014 by EMA. It defines off-label use as "situations where a medicinal product is intentionally used for a medical purpose not in accordance with the authorised product information. Off-label use includes use in non-authorised paediatric age categories."13

The principal European initiative to address off-label use has been the adoption of Regulation (EC) No 1901/2006 (Paediatric Regulation). ${ }^{14}$ This regulation, which came into force in 2007, effectively managed to increase the number of registered pediatric medicines as well as improve the information on the use of medicinal products in children. ${ }^{15}$ Nonetheless, recent population studies conducted in various European countries reveal that the incidence of pediatric off-label prescribing in primary care ranges $11 \%$ to $51 \% .^{16,17}$ In a recently published drug utilization study, Ellul et al reported the incidence of offlabel pediatric use of medicines in Malta to be $45 \%,{ }^{18}$ citing the failure by prescribers to follow the recommendations detailed in the summary of product characteristics as one of the principal contributing factors. Pursuant to this, Ellul et al found that this was mainly caused by inconsistencies in the summaries of product characteristics. Although medicines may be identical with respect to the active ingredient and formulation, if marketed by different marketing authorization holders, the information found in the summaries of product characteristics may differ, leading to off-label prescribing by physicians. ${ }^{18,19}$

One of the most compelling illustrations of inconsistencies in the product literature that has given rise to off-label use concerns etanercept powder for injection. The summary of product characteristics of etanercept, centrally authorized by EMA, includes as an indication the treatment of juvenile idiopathic arthritis (JIA) in patients "who have had an inadequate response to, or who have proved intolerant of, methotrexate." However, this indication was approved by EMA before methotrexate was actually licensed for the treatment of JIA. ${ }^{21,22}$ In view of this fact, for a number of years, the summary of product characteristics of etanercept encouraged the off-label use of 
methotrexate in JIA, since methotrexate was not licensed for the treatment of JIA. However, it is important to consider that the safety and efficacy of methotrexate in JIA has been well documented for many years, even before this indication was effectively included in the summary of product characteristics of methotrexate. ${ }^{22}$

This example clearly demonstrates that the use of medicines in an off-label manner does not necessarily mean that evidence on the safety and effectiveness of medicines is unavailable. In fact, it has been proposed that failure to use medicines in an offlabel manner in specific scenarios, under the appropriate standard of care, can translate into malpractice, since this would constitute the most rational clinical decision to take, when one considers the risk-benefit ratio and lack of suitable alternatives. $^{23-25}$

\section{Research Question, Hypothesis, and Aim}

Off-label prescribing has been reported to primarily stem from the lack of harmonization in the product literature which leads to variable prescribing habits in children. The research question was thus whether the registration procedures of medicines used in Malta actually create an idiosyncratic setting whereby product literatures of medicines relating to the same active ingredient(s) are effectively licensed with divergent information.

The hypothesis which entailed was that specific registration procedures in Malta inadvertently give rise to off-label use of medicines in children. The aim was to identify those legislative provisions that regulate the registration of medicines in such a way as to lead to discrepancies in the product literature.

\section{Methods}

A literature review was conducted in Pubmed-Medline to investigate any reported instances where registration procedures implemented by member states could have inadvertently led to off-label use of medicines. The following term associations in the title were used: "(Off-label[title/abstract]) AND (Registration[title] OR mutual recognition [title] OR decentralised procedure [title] OR centralised procedure [title] OR line extension [title] OR parallel importation [title] OR national [title] OR 126 [title] OR European Union [title] OR Europe [title] OR Member State [title])."

A literature review of pharmaceutical legislation governing both European and Maltese registration procedures was also carried out. European legislation was accessed at EudraLex, a web portal that contains legislative texts governing medicines in the EU (ec.europa.eu/health/documents/eudralex). Furthermore, European guidance documents and relevant published documents were reviewed in the web portals of the EMA (ema.europa.eu) and the Co-ordination group for Mutual recognition and Decentralised procedures-human (CMDh; $\mathrm{hma} . e u / \mathrm{cmdh} . \mathrm{html})$. Maltese pharmaceutical legislation was accessed at Justice Services, a web portal that contains legislative texts in Malta (justiceservices.gov.mt). The web portal of the Maltese Licensing authority (medicinesauthority.gov.mt) was also reviewed for any relevant guidance documents.

In the study investigating the off-label incidence of pediatric medicines, ${ }^{18}$ Ellul et al found that the respiratory system and antibiotics were the most commonly prescribed drugs in children in Malta. Similar findings have been reported by other investigators. ${ }^{26-31}$ In view of this fact, the authors reviewed the product literature of those respiratory medicines and antibiotics that had been prescribed in an off-label manner in the study by Ellul et al. ${ }^{18}$ These medicines were classified according to the Anatomical Therapeutic Chemical (ATC) system by using the Guidelines for ATC classification and Defined Daily Dose assignment. ${ }^{32}$ Subsequently, the product literature, containing the same active ingredient(s) but produced by different marketing authorization holders, were compared with each other to screen for inconsistencies between them. This was done in order to review whether and how different registration procedures used for these medicines contributed to divergences in the product literature and subsequently to off-label use by prescribers. Similarly to the study by Ellul et al, ${ }^{18}$ off-label use of medicines was defined as instances when medicines are not prescribed in accordance with their summary of product characteristics with respect to age, dose, indication as well as frequency, duration, and route of administration.

\section{Results}

Pubmed-Medline did not contain any publications that investigated whether registration procedures adopted by the different member states actually led to off-label use. During the review of pharmaceutical legislation, the authors found that Article 11 of Directive 2001/83/EC could contribute to off-label prescribing of generic medicines in Malta. Furthermore, during the literature review of respiratory medicines and antibiotics, the authors identified 3 national registration mechanisms that potentially led to inconsistencies in the product literature and, subsequent to this, off-label use of medicines in children. These are article 126a of Directive 2001/83/EC, line extensions, and parallel importation.

\section{Article II of Directive 200 I/83/EC}

Apart from governing the production, distribution and use of medicinal products for human use within the EU, Directive 2001/83/EC also makes direct reference to intellectual property. According to Article 11, when applying for a generic marketing authorization in a specific member state through either a European or national authorization route, "those parts of the summary of product characteristics of the reference medicinal product referring to indications or dosage forms which were still covered by patent law at the time when a generic medicine was marketed need not be included." ${ }^{2}$ The purpose of this provision is the avoidance of delays in the production of generic medicine. Article 11 has been transposed in Malta as Article 8 of the Medicines (Marketing Authorisation) Regulations (SL 458.34). ${ }^{9}$ 
In view of Article 11, in 2012, the co-ordination group for mutual recognition and decentralized procedures recommended the inclusion of a standard statement (blue-box) in the patient leaflet of generic medicines, where applicable, " $<$ active substance $>$ which is contained in $<$ product $><$ may also be/is also $>$ authorised to treat other conditions which are not mentioned in this leaflet. Ask your doctor or pharmacist if you have further questions." ${ }^{, 33}$ However, it is up to each member state to decide whether a blue-box is required in the patient leaflet of generic medicines marketed within their territory, where applicable. In fact, only 6 member states require the inclusion of a blue-box: Denmark, Finland, Iceland, the Netherlands, Norway, and Sweden. ${ }^{34}$

Although Malta does not require the inclusion of a blue-box in its product literature, it may still source medicines from countries which require a blue-box. In fact, the authors have identified medicines which have been registered in Malta and whose marketing authorization holder is registered in Denmark, Iceland, the Netherlands, Norway, and Sweden. In view of this fact, similarly to what might happen in these Nordic countries, Maltese prescribers may interpret a blue-box to imply that any generic medicines sourced from these countries may be recommended for those patent-protected indications, even if these indications are not mentioned in the product literature of the generic medicines. In this case, this may be justified from a clinical and ethical perspective, since the patent-protected indications would have been positively reviewed by competent authorities in other member states, during their registration phase. Nonetheless, when physicians prescribe generic blue-box medicines for patent-protected therapeutic indications, this would potentially give rise to off-label use since the patent-protected indications would not be included in the product literature of those same generic medicines. Notwithstanding this, the authors found that the relevance of this finding on off-label use of medicines is nonsignificant for Malta since the number of medicines sourced from Nordic countries is currently limited.

\section{Article 126(a) of Directive 200 I/83/EC}

The cornerstone of the article 126a registration mechanism is that the product literature of medicines authorized in Malta through this procedure is identical to the product literature of the reference medicine in another member state (country of source). As such, medicinal products imported through an article 126a provision need to have a valid marketing authorization in the country of source and are marketed on the Maltese market after the Licensing authority approves the English/Maltese version of the product literature, that is, summary of product characteristics, patient leaflet and outer carton. If the documents authorized in the country of source are not in English, the product literature submitted to the Maltese Licensing authority should be a notarized or certified English/Maltese translation of the aforementioned documents. Although the Licensing authority can technically issue numerous article 126a licenses to different wholesale dealers for the same medicinal product, sourced from different member states, this registration process should only be used for "justified public health reasons" when other registration processes are not feasible. $^{35}$

Member states are also obliged to inform the European Commission when they avail themselves of this provision. As of March 29, 2016, according to the online list published by the European Commission (ec.europa.eu/health/documents/com munity-register/html/index_en.htm), only 7 member states have used this provision to date: Lithuania (once), Portugal (twice), Hungary (4 times), Latvia (5 times), Poland (12 times), Cyprus (713 times), and Malta. According to the Maltese Licensing Authority's database (medicinesauthority.gov.mt), as of March 29, 2016, 1877 out of 5025 medicines (37\%) available on the Maltese market had a valid article 126a license. Medicines authorized through centralized authorization procedures have not been included in this equation since the great majority are not marketed in Malta. As such, Malta is, by far, the most frequent user of this "Cyprus clause." These medicinal products have been sourced from Austria, Belgium, Bulgaria, Cyprus, Czech Republic, Denmark, Estonia, France, Germany, Greece, Hungary, Ireland, Italy, Netherlands, Poland, Portugal, Romania, Slovakia, Slovenia, Spain, and the United Kingdom. The manner in which Malta interpreted article 126a of Directive 2001/83/EC allows it to issue numerous article 126a authorizations for the same active ingredient. As an example, currently there are 35 different article 126a authorizations for simvastatin preparations. This approach has been criticized by the Matrix Insight study, commissioned by the European Commission. ${ }^{36}$ The Matrix Insight study states that if a product containing a specific active ingredient has been authorized by a member state, there is no public health need to authorize additional products with the same active ingredient through the article 126a registration route.

Medicines, containing the same active ingredient(s) and imported from different member states via the article 126a provision, can be authorized by the Maltese Licensing authority with divergent product literatures. This stems from the fact that different source countries may adopt differing posology recommendations for the same active ingredient(s). The confusing scenario that entails when prescribers recommend article 126a medicines can be demonstrated by the following case. Malta sources many medicines from the United Kingdom. In fact, according to the Maltese Licensing Authority's database (medicinesauthority.gov.mt), as of 29 March 2016, 1705 out of 5025 medicines (34\%) authorized in Malta have a marketing authorization holder which is registered in the United Kingdom. Since 2010, the United Kingdom's competent authority (MHRA) increasingly started to restrict the use of specific cough and cold medications for young children, including xylometazoline, oxymetazoline, pseudoephedrine, guaifenesin, diphenhydramine, promethazine, triprolidine, codeine, pholcodine and dextromethorphan. Taking as an example a product sourced in Malta from the United Kingdom, containing 
dextromethorphan hydrobromide $7.5 \mathrm{mg} / 5 \mathrm{~mL}$, when Maltese physicians prescribe it for a child $<12$ years, it is considered to be off-label for age. The reason for this is that, similarly to the product found in the United Kingdom, the product literature authorized in Malta specifies that it is licensed in children $>12$ years of age. ${ }^{37}$ However, the authors found that the product literature of medicines sourced in Malta via the article 126a procedure from member states, other than the United Kingdom, can still recommend the use of such medicines in young children. Thus, if a Maltese physician prescribes an article 126a medicinal product, containing dextromethorphan hydrobromide $15 \mathrm{mg} / 5 \mathrm{~mL}$, triprolidine hydrochloride $1.25 \mathrm{mg} / 5 \mathrm{~mL}$, pseudoephedrine hydrochloride $20 \mathrm{mg} / 5 \mathrm{~mL}$, and guaifenesin $100 \mathrm{mg} / 5 \mathrm{~mL}$, originating from Cyprus, for a 2-year-old child, this is not off-label. The reason for this is that the product literature authorized in Malta specifies that it is licensed in children $>2$ years of age. ${ }^{37}$

Physicians are generally familiar with one standard prescribing regime for a particular active ingredient or combination of active ingredients. In fact, in a separate study, Ellul et al found that divergent dosing recommendations, as seen above, are interpreted by Maltese prescribers to mean that these medicines can still be safely prescribed in the younger age groups. ${ }^{38}$ In such cases, unintended off-label prescribing practices arise because prescribers cross-refer to divergent product literatures of medicines containing the same or similar ingredients. Further to this, from a clinical perspective, cough and cold preparations containing pseudoephedrine, dextromethorphan, triprolidine, and guaifenesin were found to exhibit a negative benefit-risk profile in young children. In keeping with this, the United Kingdom's MHRA recommended that medicinal products containing "illogical" combinations, such as antihistamines and expectorants, should be phased out. ${ }^{39}$ The BNF for Children also specifies that the rationale for some compound cough preparation is dubious, and that there is no evidence that any drug can specifically facilitate expectoration. ${ }^{40}$ In conclusion, the use of cough and cold preparations in young children may subject them to unnecessary adverse reactions with no significant therapeutic benefit.

\section{Line Extensions}

This research also identified instances where medicines authorized through line extensions exhibited divergent product literatures. This was caused because section 4.2 of the summary of product characteristics was not updated by the marketing authorization holder to reflect the most recent evidence-based clinical practice guidelines. Subsequently, this caused a divergence from the product literature of similar products within the same therapeutic class. In view of this, when physicians prescribe the medicinal product according to the most recent clinical information, this would not be in line with the licensed summary of product characteristics, and thus, this would constitute off-label use. The following is an example. When Maltese physicians prescribe $1 \mathrm{~g}$ co-amoxiclav tablets, sourced in
Malta from Cyprus, for a 10-year-old child weighing $40 \mathrm{~kg}$, it is considered to be off-label for age. The reason for this is that the summary of product characteristics of this product, authorized through a line extension, specifies that it is licensed in children $>12$ years of age.$^{37}$ However, if the same physician prescribes another medicinal product containing $1 \mathrm{~g}$ co-amoxiclav, sourced from Ireland, for the same child, this would not be considered to be off-label. The reason for this is that the summary of product characteristics of this medicinal product specifies that it is licensed in children $>40 \mathrm{~kg} .{ }^{37}$

Pursuant to this finding, the authors found that in 2009, the product literature of all co-amoxiclav preparations across all member states were reviewed by EMA, through an Article 30 referral, in order to harmonize the product information. That same year, EMA concluded that the posology recommendations should be revised to include weight considerations instead of age considerations. Thus, use of the product in "adults and children over 12 years" was changed to use in "adults and children weighing $40 \mathrm{~kg}$ and over." ${ }^{41}$ However, when the license of the above-mentioned Cypriot co-amoxiclav tablets was renewed by the Maltese Licensing authority in 2012, the posology section of the product literature was not streamlined with the recommendations by EMA. This was found to lead to off-label use of the Cypriot product in the pediatric population. Interestingly, in 2012 the Maltese Ministry of Health acknowledged that almost one in two Maltese children are overweight or obese. ${ }^{42}$ Thus, it is highly likely that physicians encounter cases where children who are $<12$ years weigh more than $40 \mathrm{~kg}$. Nonetheless, in view of the relatively small number of line extensions granted in Malta, the significance of this finding is limited.

\section{Parallel Importation}

Another national registration procedure which was found to potentially contribute to off-label prescribing in Malta is parallel importation. Although the main benefit expected for this practice is that patients avail themselves of a lower price of medicines, it has been acknowledged that such benefit is practically nonexistent for Malta. ${ }^{43}$ The main reason for this is that in the community setting, parallel imported medicines have identical consumer prices to medicines that are not parallel imported. Thus, financial benefits are principally intended for parallel importers, and pharmacy owners who are offered better bonuses by parallel importers in order to stock and dispense their product.

Similar to article 126a products, medicines that are parallel imported in Malta need to have a valid marketing authorization in the country of source and are introduced on the Maltese market after the Maltese Licensing authority approves the English/Maltese translation of the product literature. If the documents authorized in the country of source are not in English, the product literature submitted to the Maltese Licensing authority should be a notarized or certified English/Maltese translation of the aforementioned documents. 
The parallel imported product should be identical to, or have no significant therapeutic difference from, the medicine that was initially authorized on the Maltese market. ${ }^{8}$ However, from a regulatory perspective, the medicinal product that was initially authorized on the Maltese market and the parallel imported products are considered as separate medicinal products with separate sets of product literatures since they possess separate licenses.

The Licensing authority can issue numerous parallel importation licenses to different wholesale dealers for medicines sourced from different member states. According to the Maltese Licensing Authority's database (medicinesauthority. gov.mt), as of March 29, 2016, a total of 309 out of 5025 medicines $(6 \%)$ have been authorized in Malta via parallel importation. Notwithstanding the fact that the composition is identical, the authors found instances where the product literatures of parallel imported medicinal products and the medicine that was initially authorized on the Maltese market differed slightly with respect to the posology recommendations. The reason for such differences is that medicinal products may be marketed in different member states with slightly different product literatures. This is also a potential source of off-label prescribing. However, in view of the nonsignificant posology differences that have been identified between medicinal products that were initially authorized on the Maltese market and their parallel imported products, the impact of parallel importation on off-label use of medicines in Malta is limited.

\section{Discussion}

With the exception of article 11 of Directive 2001/83/EC, which also applies to European registration procedures, we did not identify discrepancies in the product literature of medicines authorized through European registration mechanisms, that is, centralized authorization procedure, mutual recognition procedure and decentralized procedure. The reason for this is that such procedures entail the simultaneous review of the same marketing authorization application, including the product literature, by various member states. Such thorough clinical appraisal leads to harmonized summaries of product characteristics and patient leaflets across all concerned member states. On the other hand, the national registration procedures implemented by Malta were found to potentially lead to differences in the product literature of medicines containing the same active ingredient, giving rise to off-label use. Of these, article 126a of Directive 2001/83/EC was found to be the main potential contributing factor for such differences.

European legislation provides for the free movement of medicinal products between member states in order to optimize the provision of health care, promote public health, and at the same time safeguard intellectual property. In order to ensure an adequate provision of pharmaceutical care, small member states like Malta import almost all of their medicinal products from other countries. Immediately following EU accession, medicines available in Malta dropped by $83 \%$. The reason for this was that pharmaceutical companies did not consider it pharmacoeconomically feasible to submit the required documentation to meet the regulatory requirements for them to continue to sell medicines on the small Maltese market. ${ }^{36}$ This caused shortages of many medicines, including pediatric ones. Thus, in 2006 the Maltese Licensing authority implemented a simpler national registration mechanism to mitigate these medicine shortages, that is, article 126a of Directive 2001/83/EC. Article 126a was considered a better alternative to article 5(1) of Directive 2001/83/EC as a route to register medicines nationally, in cases where there are more than a few patients. ${ }^{43}$ Article 5(1) states, "A Member State may, in accordance with legislation in force and to fulfil special needs, exclude from the provisions of this Directive medicinal products supplied in response to a bona fide unsolicited order, formulated in accordance with the specifications of an authorized health-care professional and for use by an individual patient under his direct personal responsibility.",2

The implementation of article 126 a procedure was indeed successful in that it reversed the steady decline in the registration of medicines in Malta. However, the raison d'etre of this registration procedure is that the medicinal product, as authorized in Malta, is identical to the reference product found in the source country. As such, different member states may authorize, via national procedures, different clinical recommendations with respect to specific active ingredients in their territories. This would result in important differences in sections 4.1 and 4.2 of the summary of product characteristics, as well as in the information found within the patient leaflet. This stance, which has been acknowledged by the European Commission, ${ }^{44}$ means that following the registration procedure, medicinal products may have different summaries of product characteristics and package leaflets in different member states. Subsequent to this, variable prescribing practices of the same active ingredient may arise across different member states.

In Malta, numerous article 126a licenses may be granted to medicines containing the same active ingredients. This means that any divergent recommendations within the product literature of these medicines, as found in different member states, are mirrored in the product literature licensed in Malta when these medicines are registered in Malta. Considering that Malta is the member state that, by far, has issued the most article 126a authorizations (1877 licenses from 21 member states), this finding is particularly significant. The authors found this registration route to be the main source of divergent information in the product literature of pediatric medicines containing the same active ingredients. When physicians cross-refer to different product literatures, this leads to unintended off-label prescribing in children. In fact, the "General Report on Experience Acquired as a Result of the Application of the Paediatric Regulation," published by the European Commission, acknowledges the fact that physicians may not always realize or consider that the manner in which they prescribe medicinal products may, in fact, constitute off-label use. ${ }^{45}$ 
In view of this, the European Commission has devised mechanisms through which the product literature across different member states can be harmonized. Such referral procedures include Article 30 of Directive 2001/83/EC, used when "Member States have adopted divergent decisions concerning the authorization of the medicinal product or its suspension or revocation." 2 The Article 30 referral procedure is intended to be used when member states adopt different recommendations, including different indications, contraindications or posologies, in the product literature. In this case, the only differences that would be permitted relate to, example, the name of the marketing authorization holder, legal supply status, and certain pharmaceutical particulars (eg, shelf life and storage conditions). ${ }^{44}$ Such harmonization approaches would effectively decrease the off-label use of medicines in member states.

\section{Conclusion}

This is the first study to investigate the relationship between registration procedures in a specific member state and off-label prescribing in its territory. While acknowledging that off-label prescribing by physicians is multifactorial, the authors found that for Malta, the principal registration route that potentially contributes to off-label prescribing in children relates to article 126a of Directive 2001/83/EC.

The regulation of medicinal products does not halt upon the granting of a marketing authorization license. It is the obligation of all marketing authorization holders, member states, as well as the European Commission and EMA to ensure that transnational safe and effective prescribing practices are promoted throughout the marketing authorization life cycle of medicines. Pursuant to this, periodic appraisals should be carried out in order to harmonize the product literature with best clinical practice guidelines. Furthermore, as advocated by other authors, dosing recommendations for specific age groups should be streamlined for medicines of the same therapeutic class. ${ }^{46}$ In view of this, it is also strongly recommended that European-wide referral procedures are triggered by member states, including Malta, and any recommendations implemented in a timely manner.

It would be interesting if similar reviews are conducted in other member states. Since Cyprus is also a frequent user of the article 126a provision, it is recommended that Cyprus investigates the relationship between this registration procedure and off-label prescribing. It is also recommended that the relationship between Article 11 of Directive 2001/83/EC and off-label prescribing practices be reviewed in those member states that adopt its provision, that is, Denmark, Finland, Iceland, Netherlands, Norway, and Sweden.

\section{Declaration of Conflicting Interests}

The author(s) declared no potential conflicts of interest with respect to the research, authorship, and/or publication of this article.

\section{Funding}

The author(s) received no financial support for the research, authorship, and/or publication of this article.

\section{References}

1. Commission of the European Communities. Consolidated version of the treaty on the functioning of the European Union. http://eur-lex.europa.eu/legal-content/EN/TXT/?uri=celex $\% 3$ A12012E\%2FTXT. Published October 26, 2012. Accessed May 2016.

2. Commission of the European Communities. Directive 2001/83/ EC of the European Parliament and of the Council of 6 November 2001 on the Community code relating to medicinal products for human use. http://eur-lex.europa.eu/legal-content/EN/TXT/? qid $=1462828482006 \&$ uri=CELEX:32001L0083. Published 2001. Accessed May 2016.

3. Commission of the European Communities. Council Directive 65/ 65/EEC of 26 January 1965 on the approximation of provisions laid down by Law, Regulation or Administrative Action relating to proprietary medicinal products. http://eur-lex.europa.eu/legalcontent/EN/TXT/?uri=CELEX\%3A31965L0065. Published 1965. Accessed May 2016.

4. Laws of Malta. Medicines Act (Act III of 2003). Chapter 458. http://www.justiceservices.gov.mt/DownloadDocument.aspx? app $=$ lom \&itemid $=8924 \& 1=1$. Published 2003. Accessed May 2016.

5. Maltese Medicines Authority. Annual Report 2015. http:// www.medicinesauthority.gov.mt/file.aspx?f=2818. Accessed May 2016.

6. Commission of the European Communities. Commission Regulation (EC) No 1234/2008 of 24 November 2008 concerning the examination of variations to the terms of marketing authorisations for medicinal products for human use and veterinary medicinal products. http://eur-lex.europa.eu/legal-content/EN/TXT/? qid $=1462829026743 \&$ uri=CELEX:32008R1234. Published 2008. Accessed May 2016.

7. Commission of the European Communities. Communication on parallel imports of proprietary medicinal products for which marketing authorisations have already been granted. COM(2003) 839 final. http://ec.europa.eu/health/files/eudralex/vol-1/com_2003_ 839/com_2003_839_en.pdf. Published December 30, 2003. Accessed May 2016.

8. Laws of Malta. Subsidiary legislation 458.40. Parallel Importation of Medicinal Products Regulations. http://www.justiceservi ces.gov.mt/DownloadDocument.aspx app=lom\&itemid= 11278\&l=1. Published October 12, 2004. Accessed May 2016.

9. Laws of Malta. Subsidiary legislation SL458.34 Medicines (Marketing Authorisation) Regulations. http://www.justiceservices. gov.mt/DownloadDocument.aspx?app=lom\&itemid=11272\&l=1. Published October 26, 2007. Accessed May 2016.

10. Commission of the European Communities. Guideline on the summary of product characteristics (SmPC). http://ec.europa.eu/ health/files/eudralex/vol-2/c/smpc_guideline_rev2_en.pdf. Published September 2009. Accessed May 2016. 
11. Ellul IC, Grech V. Off-label and unlicensed paediatric prescribing in a community setting: a prospective longitudinal cohort study in Malta. Paediatr Int Child Health. 2014;34:12-18.

12. Commission of the European Communities. Directive 2001/82/ EC of the European Parliament and of the Council of 6 November 2001 on the Community code relating to veterinary medicinal products. http://ec.europa.eu/health/files/eudralex/vol-5/dir_ 2001_82/dir_2001_82_en.pdf. Published 2001. Accessed May 2016.

13. European Medicines Agency. Guideline on good pharmacovigilance practices (GVP). Annex I - Definitions Rev 3. Report No: EMA/876333/2011 Rev 3. http://www.ema.europa.eu/docs/en_ GB/document_library/Scientific_guideline/2013/05/WC500143 294.pdf. Published April 2014. Accessed May 2016.

14. Commission of the European Communities. Commission Regulation (EC) no 1901/2006 of the European Parliament and of the Council of 12 December 2006 on medicinal products for paediatric use and amending Regulation (EEC) No 1768/92, Directive 2001/20/EC, Directive 2001/83/EC and Regulation (EC) No 726/ 2004. http://eur-lex.europa.eu/legal-content/EN/TXT/? qid=1462830199210\&uri=CELEX:32006R1901. Published 2006. Accessed May 2016.

15. Commission of the European Communities. Better medicines for children from concept to reality. General report on experience acquired as a result of the application of Regulation (EC) No 1901/2006 on medicinal products for paediatric use. Report No: $\operatorname{COM}(2013) 443$ final. http://eur-lex.europa.eu/legal-content/EN/ ALL/?uri=CELEX\%3A52013DC0443. Published June 2013. Accessed May 2016.

16. Morales-Carpi C, Estañ L, Rubio E, Lurbe E, Morales-Olivas FJ. Drug utilization and off-label drug use among Spanish emergency room paediatric patients. Eur J Clin Pharmacol. 2010;66: 315-320.

17. Kimland E, Odlind V. Off-label drug use in pediatric patients. Clin Pharmacol Ther. 2012;91:796-801.

18. Ellul IC, Grech V, Attard-Montalto S. Paediatric off-label and unlicensed prescribing in primary care in Malta: prospective observational drug utilisation study. Int J Risk Saf Med. 2015; 27:123-134.

19. Carnovale C, Conti V, Perrone V, et al. Paediatric drug use with focus on off-label prescriptions in Lombardy and implications for therapeutic approaches. Eur J Pediatr. 2013;172:1679-1685.

20. European Medicines Agency. Electronic Medicines Compendium. http://www.ema.europa.eu/ema/index.jsp?curl=pages/med icines/landing/epar_search.jsp\&mid=WC0b01ac058001d124. Accessed May 2016.

21. National Horizon Scanning Centre. New and emerging technology briefing. Tocilizumab (Actemra ${ }^{\mathrm{TM}}$ ) for rheumatoid arthritis and juvenile idiopathic arthritis. University of Birmingham; 2006.

22. Cummins C, Connock M, Fry-Smith A, Burls A. A systematic review of effectiveness and economic evaluation of new drug treatments for juvenile idiopathic arthritis: etanercept. Health Technol Assess. 2002;6:1-43.

23. American Academy of Pediatrics Committee on Drugs. Unapproved uses of approved drugs: the physician, the package insert, and the Food and Drug Administration: subject review. Pediatrics. 1996;98:143-145.

24. Bavdekar SB, Gogtay NJ. Unlicensed and off-label drug use in children. J Postgrad Med. 2005;51:249-252.

25. Marchetti F, Bua J, Ventura A, et al. The awareness among paediatricians of off-label prescribing in children: a survey of Italian hospitals. Eur J Clin Pharmacol. 2007;63:81-85.

26. Carnovale C, Conti V, Perrone V, et al. Paediatric drug use with focus on off-label prescriptions in Lombardy and implications for therapeutic approaches. Eur J Pediatr. 2013;172:1679-1685.

27. Lass J, Irs A, Pisarev H, Leinemann T, Lutsar I. Off label use of prescription medicines in children in outpatient setting in Estonia is common. Pharmacoepidemiol Drug Saf. 2011;20:474-481.

28. Bazzano AT, Mangione-Smith R, Schonlau M, Suttorp MJ, Brook RH. Off-label prescribing to children in the United States outpatient setting. Acad Pediatr. 2009;9:81-88.

29. Mühlbauer B, Janhsen K, Pichler J, Schoettler P. Off-label use of prescription drugs in childhood and adolescence: an analysis of prescription patterns in Germany. Dtsch Arztebl Int. 2009;106: 25-31.

30. Olsson J, Kimland E, Pettersson S, Odlind V. Paediatric drug use with focus on off-label prescriptions in Swedish outpatient carea nationwide study. Acta Paediatr. 2011;100:1272-1275.

31. Ribeiro M, Jorge A, Macedo AF. Off-label drug prescribing in a Portuguese paediatric emergency unit. Int J Clin Pharm. 2013;35: 30-36.

32. World Health Organisation Collaborating Centre for Drug Statistics Methodology. Guidelines for ATC classification and Defined Daily Dose assignment. 16th ed. http://www.whocc.no/filearc hive/publications/1_2013guidelines.pdf. Published 2013. Accessed May 2016.

33. Co-ordination group for mutual recognition and decentralised procedures-human. CMDh Questions and Answers. Usage Patents. Report No: CMDh/279/2012. http://www.hma.eu/filead $\mathrm{min} /$ dateien/Human_Medicines/CMD_h_/Questions_Answers/ CMDh-279-2012-Rev0-2012_10.pdf. Published October 2012. Accessed May 2016.

34. Co-ordination group for mutual recognition and decentralised procedures-human. Blue-Box requirements. Report No: CMDh/258/2012/Rev. 9. http://www.hma.eu/fileadmin/dateien/ Human_Medicines/CMD_h_/procedural_guidance/Application_ for_MA/CMDh_258_2012_Rev09_2016_03_clean.pdf. Published March 2016. Accessed May 2016.

35. Maltese Medicines Authority. Authorisation in line with Article 126(a) of Directive 2001/83/EC. http://medicinesauthority. gov.mt/126a. Published 2016. Accessed May 2016.

36. Matrix Insight. Study on the Availability of Medicinal Products for Human Use. http://ehtpa.eu/pdf/Matrix_report.pdf. Published December 2012. Accessed May 2016.

37. Maltese Medicines Authority. Electronic Medicines Compendium. http://medicinesauthority.gov.mt/medicinesdatabase. Published 2016. Accessed May 2016.

38. Ellul IC, Grech V, Attard-Montalto S. Maltese prescribers use of off-label and unlicensed medicines in children: perceptions and attitudes. In press. 
39. Medicines and Healthcare Products Regulatory Agency. Overview-Risk: Benefit of OTC cough and cold medicines in children. London; 2009.

40. Paediatric Formulary Committee. BNF for Children 2015-2016. BMJ Group, Pharmaceutical Press and RCPCH Publications. London; 2015.

41. European Medicines Agency. Questions and answers on the referral for Augmentin (amoxicillin and clavulanic acid). Report No: EMEA/CHMP/97898/2009 Rev 1. http://www.ema.europa.eu/ docs/en_GB/document_library/Referrals_document/Augmen tin_30/WC500014179.pdf. Published October 2009. Accessed May 2016.

42. Health Promotion and Disease Prevention Directorate. A Healthy Weight for Life: a national strategy for Malta 2012-2020. https:// health.gov.mt/en/Documents/National-Health-Strategies/hwl_ en.pdf. Published 2012. Accessed May 2016.

43. EU Secretariat. Ministry for European Affairs and Implementation of the Electoral Manifesto. Study on the Availability of Medicinal Products for Human Use. Feedback on the report by Matrix
Insight, as applicable to Malta, based on the experience of the last ten years. http://ec.europa.eu/health/files/committee/73meeting/ 73plus/malta.pdf. Published March 2014. Accessed May 2016.

44. European Commission. Notice to Applicants, Volume 2A. Procedures for Marketing Authorisation. Chapter 3-Union Referral Procedures. http://ec.europa.eu/health/files/eudralex/vol-2/ 2014-05_vol2a_chap_3.pdf. Published May 2014. Accessed May 2016.

45. Commission of the European Communities. General report on experience acquired as a result of the application of the paediatric regulation (Article 50(2) of Regulation (EC) No 1901/2006). "Experience acquired and Lessons learnt" submitted for public consultation. Report No: SANCO/D5/FS/(2012)1251190. http:// ec.europa.eu/health/files/paediatrics/2012-09_publicconsulta tion_en.pdf. Published September 2012. Accessed May 2016.

46. Ekins-Daukes S, Helms PJ, Simpson CR, Taylor MW, McLay JS. Off-label prescribing to children in primary care: retrospective observational study. Eur J Clin Pharmacol. 2004;60: 349-353. 